\title{
An Improving Hysteresis CurRent Control Method BASED ON FOC TECHNIQUe FOR INDUCTION MOTOR DRIVE
}

\author{
Cuong Dinh TRAN ${ }^{1, *}$, Pavel BRANDSTETTER ${ }^{2}$, Bach Hoang DINH ${ }^{1}$, \\ Chau Si Thien DONG ${ }^{3}$
}
${ }^{1}$ Power System Optimization Research Group, Faculty of Electrical and Electronics Engineering, Ton Duc Thang University, Ho Chi Minh City, Vietnam
${ }^{2}$ Faculty of Electrical Engineering and Computer Science, VSB-Technical University of Ostrava, Czech Republic
${ }^{3}$ Faculty of Electrical and Electronics Engineering, Ton Duc Thang University, Ho Chi Minh City, Vietnam

*Corresponding Author: Cuong Dinh TRAN (Email: trandinhcuong@tdtu.edu.vn)

(Received: 1-Feb-2021; accepted: 5-Jun-2021; published: 30-Jun-2021)

DOI: http://dx.doi.org/10.25073/jaec.202152.321

\begin{abstract}
The paper presents an improving speed control method using a field-oriented control (FOC) technique for the hysteresis current $(\mathrm{HC})$ controller in the induction motor drive. The basic principle of a controller applying hysteresis band current is comparing reference currents and the measured currents to generate switching pulses for controlling an inverter. In the typical FOC for the $\mathrm{HC}$ controller, the rotor flux angle's value will increase to infinity due to the integral algorithm's error accumulation. This problem can lead to the faulty operation of the induction motor drive (IMD) system. In this paper, a current model with the advantage of precisely determining the periodic rotor flux angle is used in the FOC technique to provide reference currents for the current controller. The rotor flux angle will periodically change according to the motor speed in the range [- $\pi$ ] d during the operation of IMD. The operation of the induction motor drive is implemented and tested by MATLAB/SIMULINK software. The simulation results have demonstrated the effectiveness of the HC control method based FOC technique with periodic rotor flux angle in controlling motor speed.
\end{abstract}

\section{Keywords}

FOC, hysteresis current controller, rotor flux, rotor flux angle.

\section{Nomenclature}

$\boldsymbol{\Psi}_{S}^{S}-$ Stator flux vector in $[\alpha, \beta]$ coordinate system.

$\Psi_{R}^{S}$ - Rotor flux vector in $[\alpha, \beta]$ coordinate system.

$i_{S}^{S}-$ Stator current vector in $[\alpha, \beta]$ coordinate system.

$i_{R}^{S}-$ Rotor current vector in $[\alpha, \beta]$ coordinate system.

$u_{S}^{S}-$ Stator voltage vector in $[\alpha, \beta]$ coordinate system.

$u_{S \alpha}, u_{S \beta}-$ Stator voltage component in $[\alpha, \beta]$ system.

$u_{S x}, u_{S y}-$ Stator voltage component in $[x, y]$ system. 
$u_{a}, u_{b}, u_{c}$ - Stator voltage component in $[a, b, c]$ system.

$i_{S x}-$ Flux current component.

$i_{S y}$ - Torque current component.

$i_{m}$ - Magnetizing current.

$R_{S}, R_{R}$ - Stator and rotor resistance.

$L_{S}, L_{R}-$ Stator and rotor induction.

$L_{m}$ - Magnetizing induction.

$T_{R}$ - Rotor time constant.

$\omega_{m}$ - Mechanical angular speed.

$p$ - Pole pair number.

$\psi_{R}-$ Nominal rotor flux.

$\gamma-$ Rotor flux angle.

\section{Introduction}

Induction motors (IMs) with outstanding manufacturing cost, size, and durability are among the most popular machine types. In the past, due to the non-linearity in control, induction motors mostly only worked in general applications with a fixed operating speed [1]. In recent times, with the development of the power electronics field, inverters, and microcontroller technology, modern control methods applied to IM have been developed to satisfy speed control applications.

Scalar control and vector control are considered two main groups of speed control methods of IMDs. The scalar control (SLC) method's principle is to keep the voltage per frequency ratio constant corresponding to rated flux by controlling the supply voltage and frequency through an inverter [2-6]. By this approach, the typical SLC method does not require feedback sensors and is not affected by machine parameter changes during operation. Thus, IMDs that applied the SLC method have fast control response and low-cost manufacturing. However, because the SLC method does not use feedback signals, it can not precisely control the rotor speed and torque [7]. On the other hand, when the motor operates at the low-speed range, the high drop voltage on the stator side can seriously affect the SLC method's control feature.

The vector control method, typically the FOC method, is a modern control method suitable for speed control applications requiring high precision. The FOC method's principle is to apply a current space vector, separated into two orthogonal components: " $i_{s x}$ and $i_{s y}$ " for the rotor flux and torque control independently [8-10]. Thus, the FOC method reduces the complexity of the non-linearity structure in the controlling IMD. Although the FOC method has a high performance in speed control, however, this method requires high machine parameter accuracy and high hardware requirements $[1,11]$.

In the IMD system applying the FOC algorithm requires feedback current and speed signals from the sensors [12]. The feedback current signal in $[a, b, c]$ stationary coordinate system is transformed into the $[x, y]$ rotating coordinate system to separate into two components: $i_{s x}$ for flux control and $i_{s y}$ for torque control. These components combine with the setting values such as flux, rotor speed, and the control algorithm to generate the reference control signal. In case the reference control signal is the voltage signals, the Pulse Width Modulation (PWM) method can be used to produce the switching pulse to control the inverter. In case this signal is current, the hysteresis current control method can be used for generating the switching pulses $[13,14]$. Although the current of IMD applying $\mathrm{HC}$ method is high ripple, however, due to its simple structure, low switching losses, and fast response, the $\mathrm{HC}$ method is preferred in practice $[15,16]$.

The rotating coordinate system in the FOC method is oriented in the rotor flux direction, as in Fig. 1. Therefore, determining the rotor flux angle is extremely important in the FOC method with the $\mathrm{HC}$ controller. A typical FOC applied for $\mathrm{HC}$ controller with the flux angle calculating form integral algorithm is presented in $[13,17$, 18]. The simulation results have demonstrated the effectiveness of this method. However, the integral algorithm's error accumulation leads to the inaccuracy of the value rotor flux angle; its value will increase to infinity. Each variable will declare a data type in the actual control model. 
And each data type has a limit; the value of the variable will automatically return to zero when it exceeds the limit of the data type. As a result, this control method may meet some problems in the actual operation when the value of the rotor flux angle overcomes the data type limitations.

This paper reviews the typical FOC method used for the $\mathrm{HC}$ controller in $[13,17,18]$ and then proposes an improvement based on the current model for calculating the rotor flux angle. The result is that the estimated flux angle is a periodic function. The periodic rotor flux angle will match the actual model and prevent data overflow of the flux variable in real operation. The simulations will implement for two cases to demonstrate the feasibility of the proposed revision.

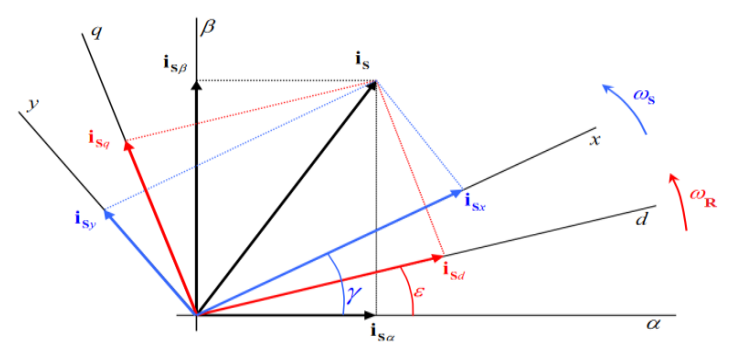

Fig. 1: Vector diagram of FOC method.

\section{The FOC method for hysteresis controller}

In this part, the FOC method's model applied for the $\mathrm{HC}$ controller in IMD is presented.

\subsection{The typical FOC method for hysteresis current controller}

The basic principle of the FOC method is that the magnetic flux control is independent of torque control. Therefore the three-phase current is feedback to the FOC loop through the current sensors, as in Fig. 2.

In the first step, the reference $i_{S x}$ component is estimated from the setup value of rotor flux by the below equation:

$$
i_{S x}^{*}=\frac{\psi_{R}^{*}}{L_{m}}
$$

The three-phase current has two functions: one is used in the $\mathrm{HC}$ controller to generate control switching pulses to the inverter, the other is applied modified Clarke's and Park's transformations to converted from $[a, b, c]$ coordinate system into $[x, y]$ rotating coordinate system, as below [17, 18]:

$$
\begin{aligned}
& {\left[\begin{array}{l}
i_{S x} \\
i_{S y}
\end{array}\right]=\frac{2}{3}} \\
& \times\left[\begin{array}{rrr}
\cos (\gamma) & \cos \left(\gamma-\frac{2 \pi}{3}\right) & \cos \left(\gamma+\frac{2 \pi}{3}\right) \\
-\sin (\gamma) & -\sin \left(\gamma-\frac{2 \pi}{3}\right) & -\sin \left(\gamma+\frac{2 \pi}{3}\right)
\end{array}\right] \\
& \times\left[\begin{array}{c}
i_{a} \\
i_{b} \\
i_{c}
\end{array}\right]
\end{aligned}
$$

The $i_{S x}$ is used to estimate the rotor flux by the transfer function as below:

$$
\psi_{R}=\frac{1}{T_{R} s+1} L_{m} i_{S x}
$$

The difference between the reference rotor speed and the measured speed is used to generate the reference torque by the PI controller. The torque combining rotor flux is used to estimate the reference $i_{S y}$ component, as below:

$$
i_{S y}^{*}=\frac{1}{p} \frac{2}{3} \frac{L_{R}}{L_{m}} \frac{T_{e}^{*}}{\psi_{R}}
$$

The $i_{S y}$ is used to estimate the rotor slip by the followings:

$$
\omega_{s l}=\frac{L_{m}}{T_{R}} \frac{i_{S y}}{\psi_{R}}
$$

The rotor flux angle " $\gamma$ " is calculated from measured rotor speed and the slip speed by Eq. (6):

$$
\gamma=\int\left(p \cdot \omega_{m}+\omega_{s l}\right) \mathrm{d} t
$$

The reference current in $[x, y]$ coordinate system combining to rotor flux angle is inverse transformed into $[a, b, c]$ system, and then sent 


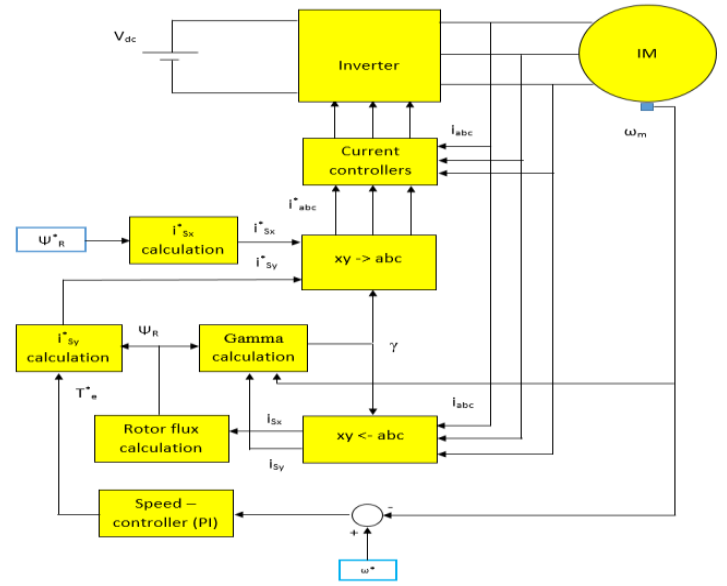

Fig. 2: Block diagram of the FOC method applied for HC controller.

to the $\mathrm{HC}$ controller to generate the switching pulses, as in block diagram.

This model's advantage is that the algorithm is simple and quickly responds to the control commands. However, the value of the rotor flux angle in the integral algorithm of Eq. (6) will increase indefinitely. This problem will seriously affect the actual performance of IMD due to the limitation of the data type.

\subsection{The FOC method using the current model for hysteresis current controller}

A current model will be applied in the proposed structure to determine the rotor flux's magnitude and rotation angle $[19,20]$, as shown in the block diagram of Fig. 3. The stator current in $[a, b, c]$ coordinate system is converted into $[\alpha, \beta]$ stationary coordinate system by Clarke's transformations, as below:

$$
\left[\begin{array}{l}
i_{\alpha} \\
i_{\beta}
\end{array}\right]=\left[\begin{array}{ccc}
\frac{2}{3} & -\frac{1}{3} & -\frac{1}{3} \\
0 & \frac{1}{\sqrt{3}} & -\frac{1}{\sqrt{3}}
\end{array}\right]\left[\begin{array}{l}
i_{a} \\
i_{b} \\
i_{c}
\end{array}\right]
$$

The current in $[\alpha, \beta]$ coordinate system combining with rotor speed to convert into $[d, q]$ rotating coordinate system corresponding to rotor

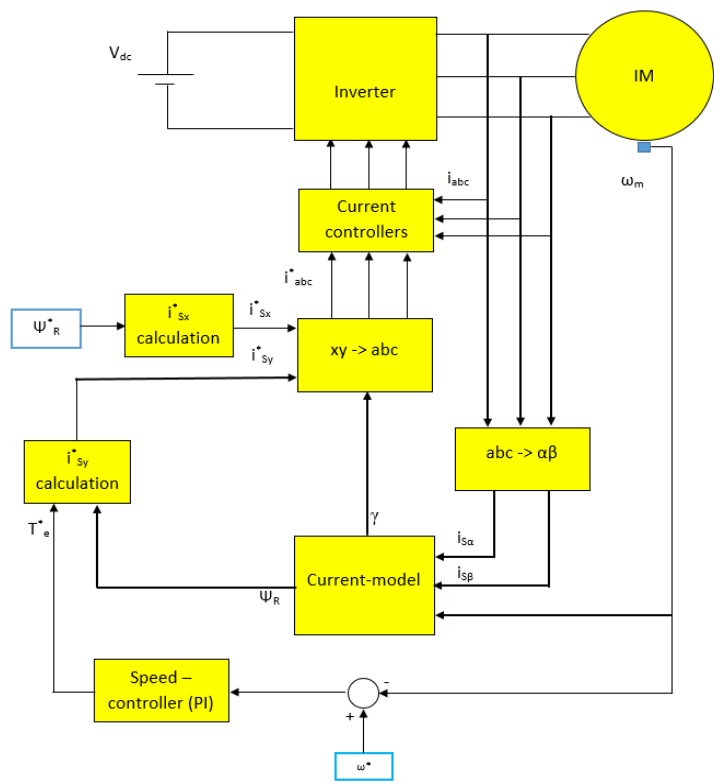

Fig. 3: Block diagram of the FOC method with current model applied for $\mathrm{HC}$ controller.

axis as below:

$$
\left[\begin{array}{c}
i_{S d} \\
i_{S q}
\end{array}\right]=\left[\begin{array}{cc}
\cos \varepsilon & \sin \varepsilon \\
-\sin \varepsilon & \cos \varepsilon
\end{array}\right]\left[\begin{array}{c}
i_{S \alpha} \\
i_{S \beta}
\end{array}\right]
$$

where $\varepsilon=\int p \omega_{m} \mathrm{~d} t$.

The magnetizing current " $i_{m}$ " in $[d, q]$ coordinate system are determined by Eq. (9):

$$
\left\{\begin{array}{l}
i_{m d}=\frac{1}{T_{R} s+1} i_{S d} \\
i_{m q}=\frac{1}{T_{R} s+1} i_{S q}
\end{array}\right.
$$

The magnetizing current in $[d, q]$ coordinate is converted back into $[\alpha, \beta]$ system to determine the amplitude of rotor flux and the flux angle, as in Eqs. (10) and (11).

$$
\begin{array}{r}
{\left[\begin{array}{l}
i_{m \alpha} \\
i_{m \beta}
\end{array}\right]=\left[\begin{array}{cc}
\cos \varepsilon & -\sin \varepsilon \\
\sin \varepsilon & \cos \varepsilon
\end{array}\right][} \\
\left\{\begin{array}{l}
i_{m}=\sqrt{\left(i_{m \alpha}^{2}+i_{m \beta}^{2}\right)} \\
\psi_{R}=L_{m} i_{m} \\
\gamma=\operatorname{arctg}\left(\frac{i_{m \beta}}{i_{m \alpha}}\right)
\end{array}\right.
\end{array}
$$

In this way, the estimated flux angle is a periodic function that is suitable with the actual control model. 
The rotor flux and rotor flux angle are used in the control algorithms to generate the reference stator currents for the FOC method with the HC controller.

\section{Simulation results}

Simulation results of two FOC methods applying for $\mathrm{HC}$ controller in speed control of IMD are presented in this section. The machine model and the inverter are extracted from the library of MATLAB/SIMULINK software. The machine parameters are listed as follows:

$$
\begin{aligned}
& P_{r}=4.0 \mathrm{~kW}, \omega_{n}=1430 \mathrm{rpm}, \\
& p=2, U_{r}=400 \mathrm{~V}, \\
& R_{S}=1.405 \Omega, R_{R}=1.395 \Omega, \\
& L_{S}=0.178 \mathrm{H}, L_{R}=0.178 \mathrm{H}, L_{m}=0.172 \mathrm{H} .
\end{aligned}
$$

Figure 4 presents the typical FOC method's control structure in MATLAB/SIMULINK environment; in this model, the amplitude and the angle of rotor flux are determined in section 2.1. Figure 5 corresponds to the control structure of the FOC method using the current model. The components of estimated rotor flux are determined by the current model as presented in section 2.2 .

The simulations in a no-load condition and a load of 10 (N.m) are implemented corresponding to various speed areas. The rotor speed, stator currents, and rotor flux responses are shown for both models.

\section{Study 1:}

The operation of the IMD system is simulated at the normal speed range in 2 seconds intervals. The reference speed is set to follow the ramp from a value of zero to $750 \mathrm{rpm}$ in 0.2 seconds in a no-load condition.

Figure 6 presents the performance of the typical FOC with HC controller in the speed control for IMD. Figure 6(a) depicts the performance of the HC control method based on the FOC technique. The rotor speed follows the set speed precisely and quickly. The current stator in Fig. 6(b) has a high ripple corresponding to the $\mathrm{HC}$ control technique's characteristic. The total har- monic distortion value of phase current (THDI) is $12.3 \%$. The flux magnitude has quickly increased and kept as a constant during the FOC method's operation, as in Fig. 6(c). The rotor flux angle increases indefinitely due to the error of accumulation of the integral algorithm in Fig. $6(d)$, leading to a problem in the experimental model due to data types' limitation. When the value of the flux angle variable is greater than the limit of data types, it can be set to zero, which can lead to a mistake control in the operation of IMD.

The FOC's performance using the current model is shown in Fig. 7 at the same simulation condition. Figure $7(\mathrm{a}, \mathrm{b}, \mathrm{c})$ present the speed characteristic, three-phase stator current, and the flux magnitude of the improvement method. The THDI value of this model is equivalent to the typical FOC. The rotor flux angle is proved as a periodic function in Fig. $7(\mathrm{~d})$, and its value varies in the range $[-\pi \pi]$ The simulation results have demonstrated the effectiveness of the improvement method.

\section{Study 2:}

The operation of the IMD system is simulated at the low-speed range in 2 seconds intervals. The reference speed is set to follow the ramp from a value of zero to $300 \mathrm{rpm}$ in 0.2 seconds with a load of 10 N.m during the IMD drive's operation time.

Figures $8(\mathrm{a}, \mathrm{b}, \mathrm{c})$ and $9(\mathrm{a}, \mathrm{b}, \mathrm{c})$ depict the performance of two FOC method. Both IMD systems have operated stably with the features of the FOC method. The THDI value of both methods is $15.9 \%$ in this case study. However, there is a difference in rotor flux angle "gamma" between the two methods. Gamma increases to infinity in Fig. 8(d), but it is a periodic function corresponding to the improvement method, as in Fig. 9(d).

The rotor flux angle in FOC with the current model is periodic, corresponding to the operating frequency of IMD. That can increase the reliability of the control method in speed control of IMD. 


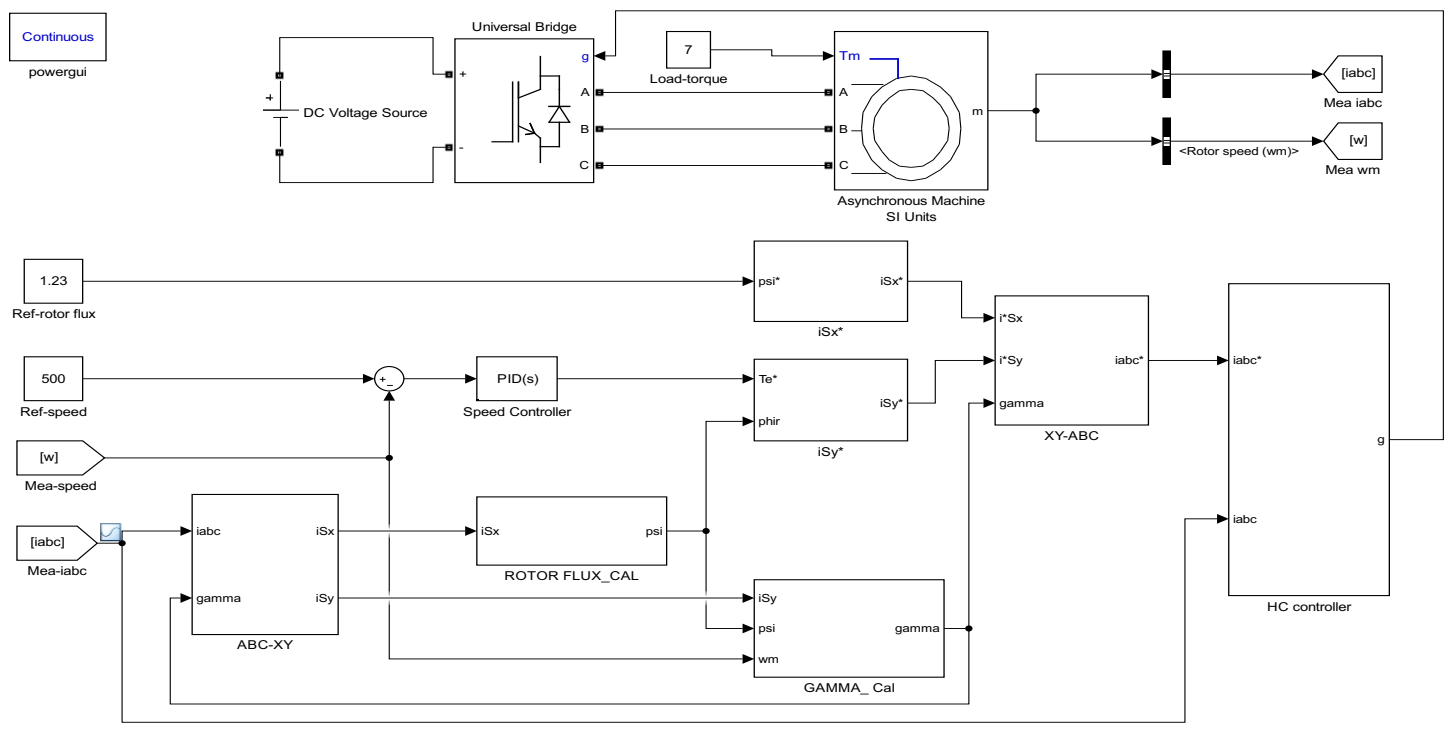

Fig. 4: Simulink-simulation structure of the typical FOC for hysteresis current controller.

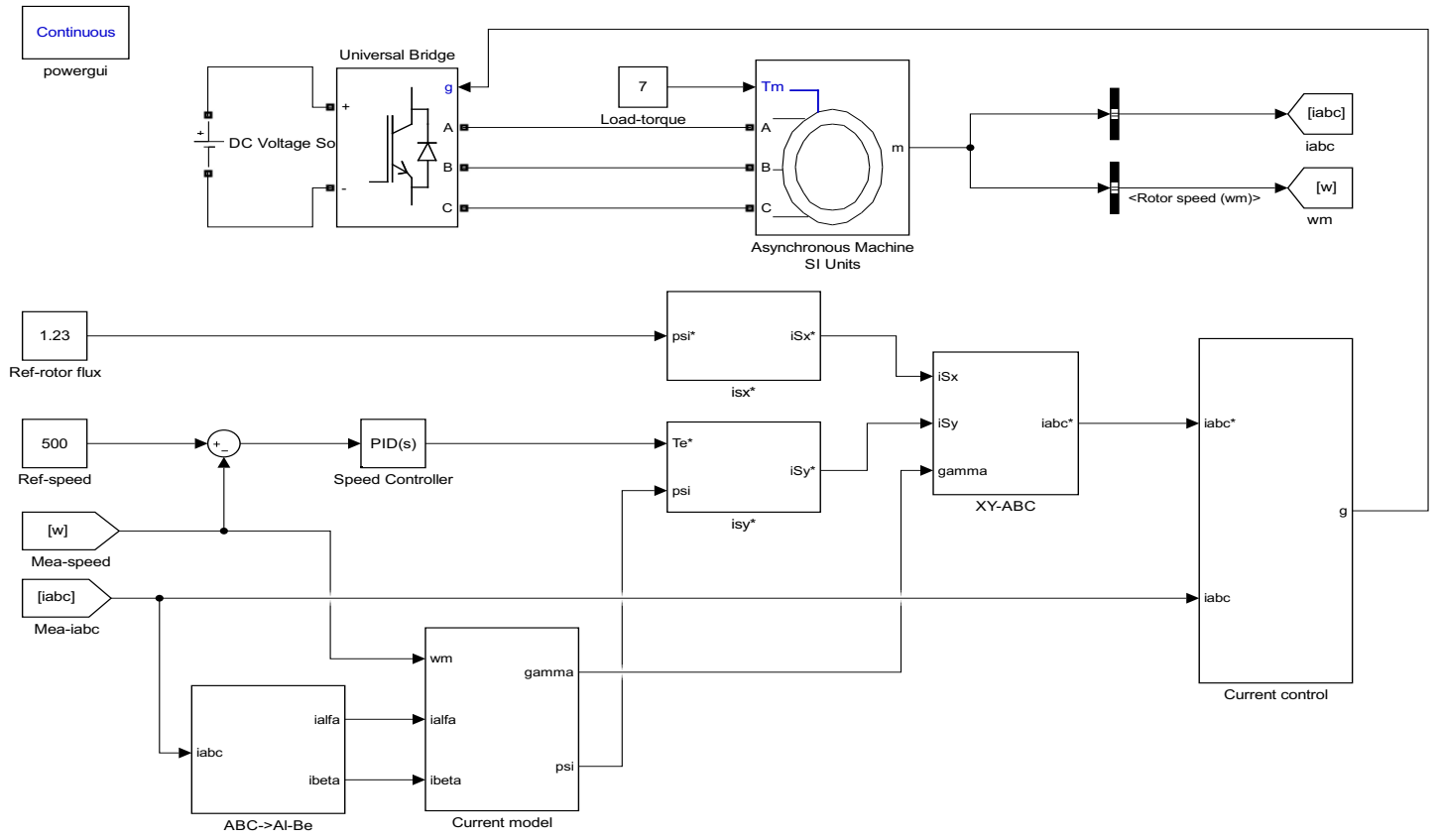

Fig. 5: Simulink-simulation structure of the FOC applying the current model for hysteresis current controller. 


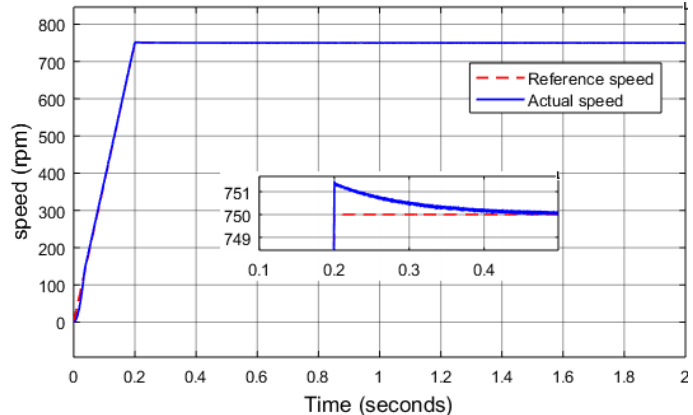

(a) Reference and actual rotor speed

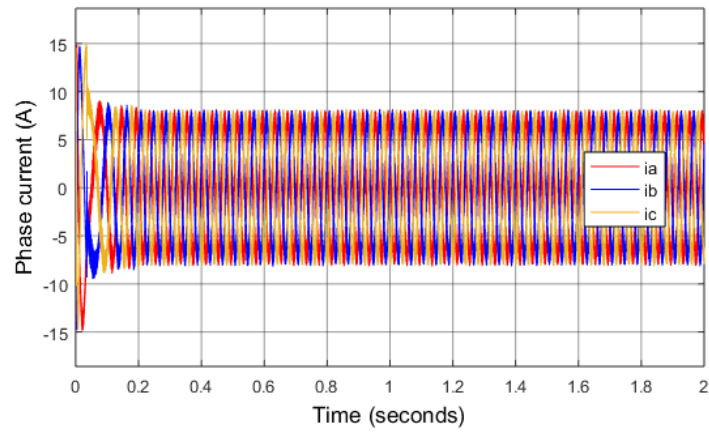

(b) Three-phase measured current

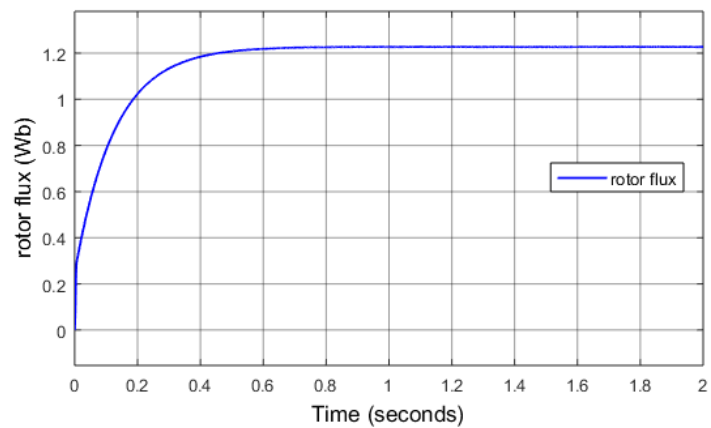

c) The amplitude of rotor flux

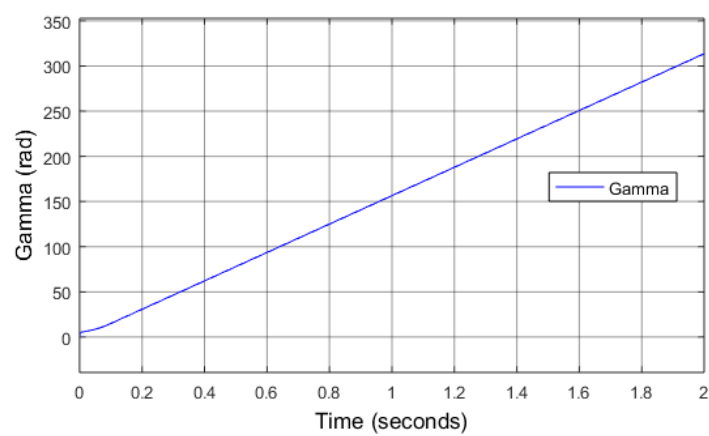

(d) Rotor flux angle

Fig. 6: Typical FOC for hysteresis current controller at a no-load condition.

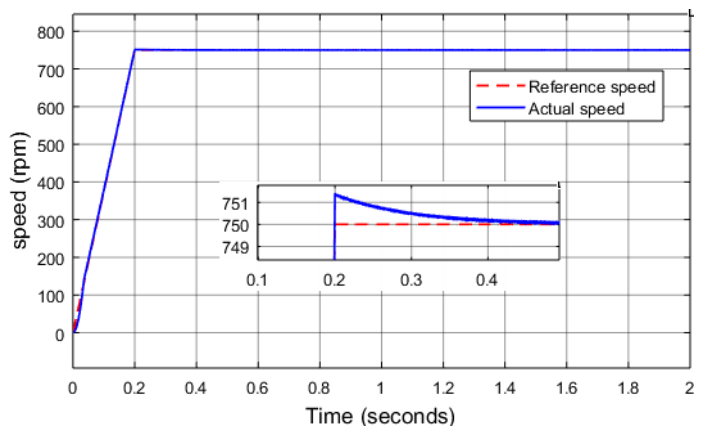

(a) Reference and actual rotor speed

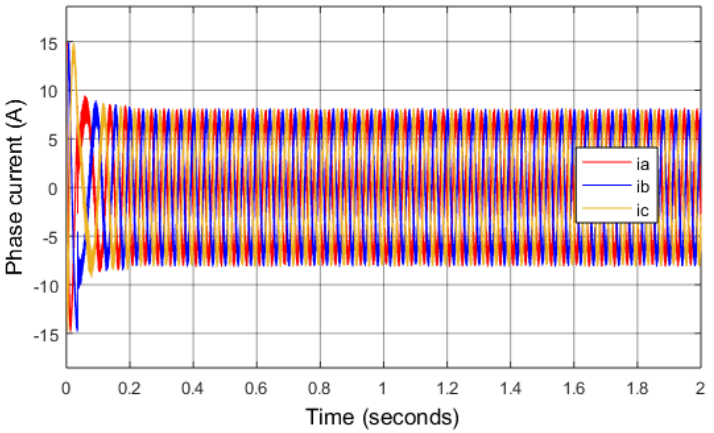

(b) Three-phase measured current

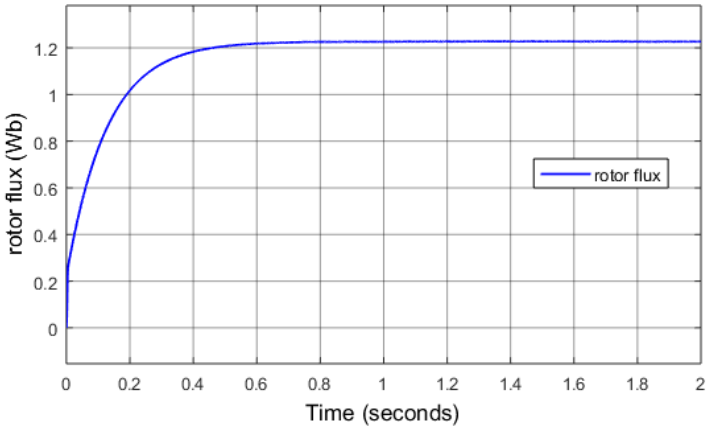

c) The amplitude of rotor flux

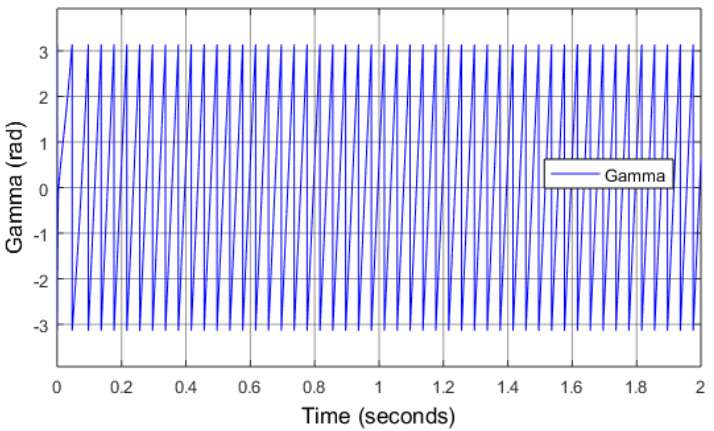

(d) Rotor flux angle

Fig. 7: The FOC using the current model for hysteresis current controller at a no-load condition. 


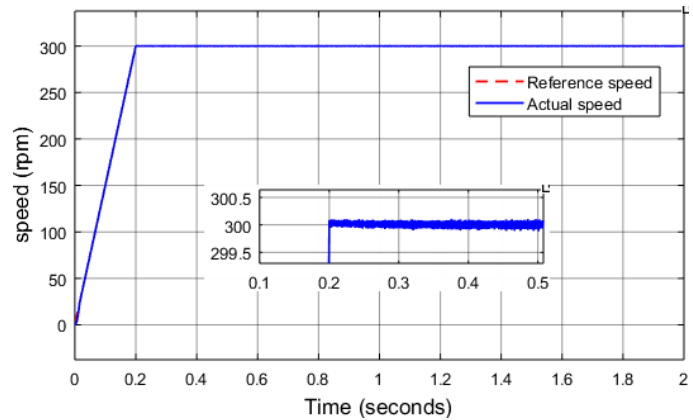

(a) Reference and actual rotor speed

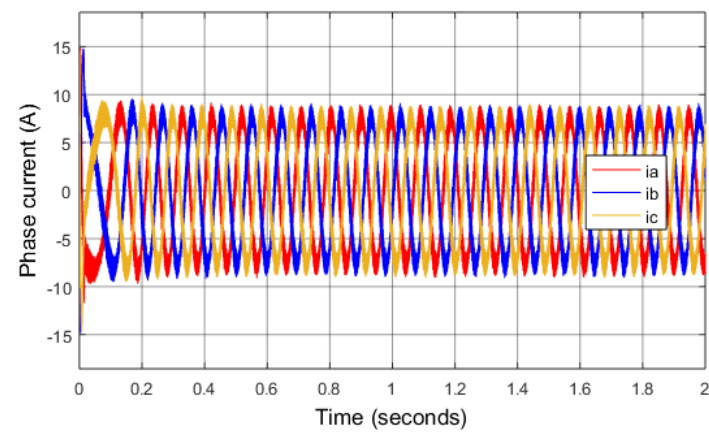

(b) Three-phase measured current

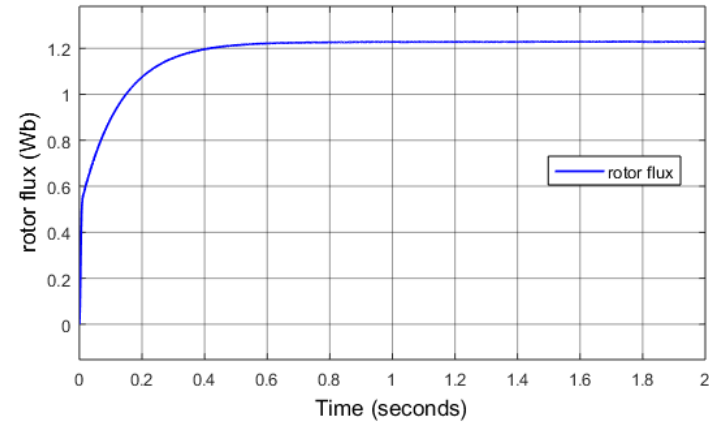

c) The amplitude of rotor flux

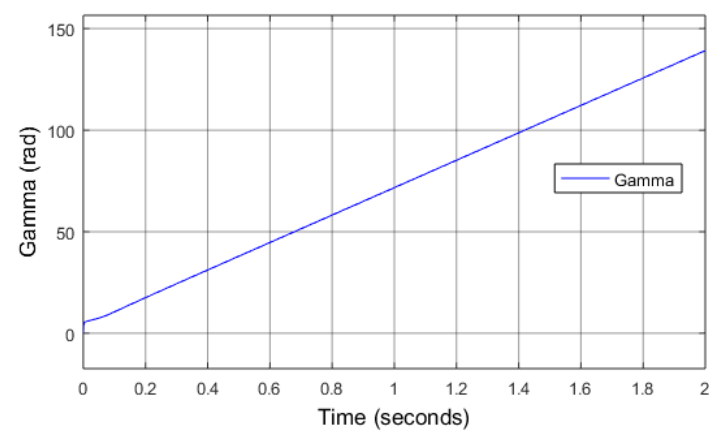

(d) Rotor flux angle

Fig. 8: Typical FOC for hysteresis current controller at a load of 10 (N.m).

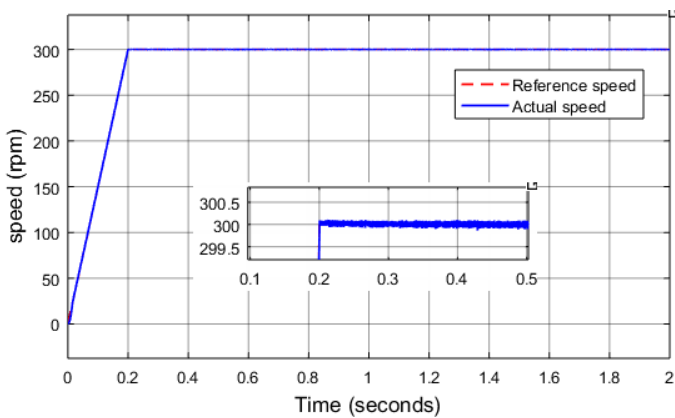

(a) Reference and actual rotor speed

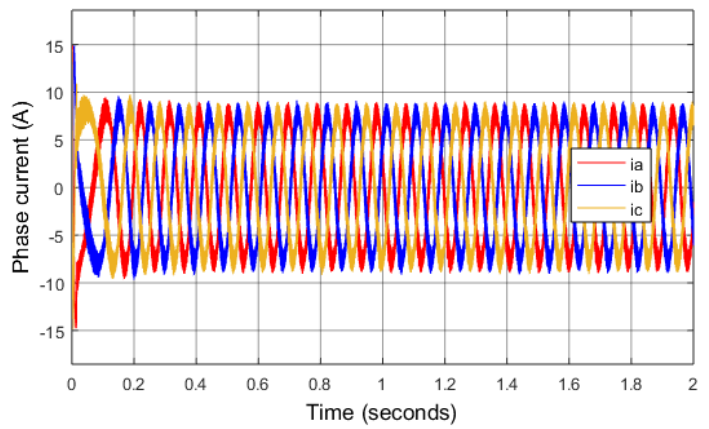

(b) Three-phase measured current

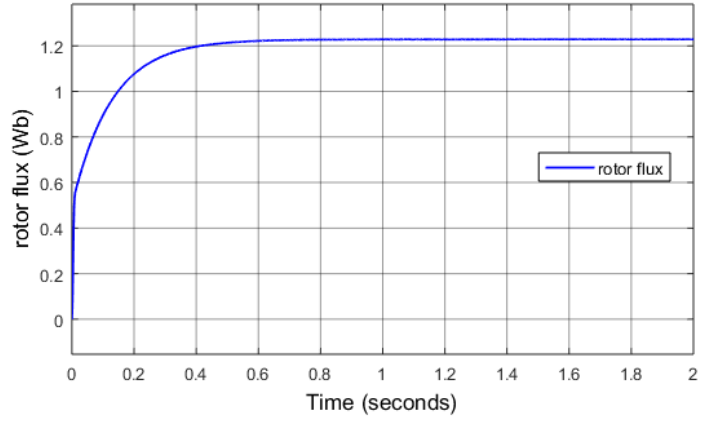

c) The amplitude of rotor flux

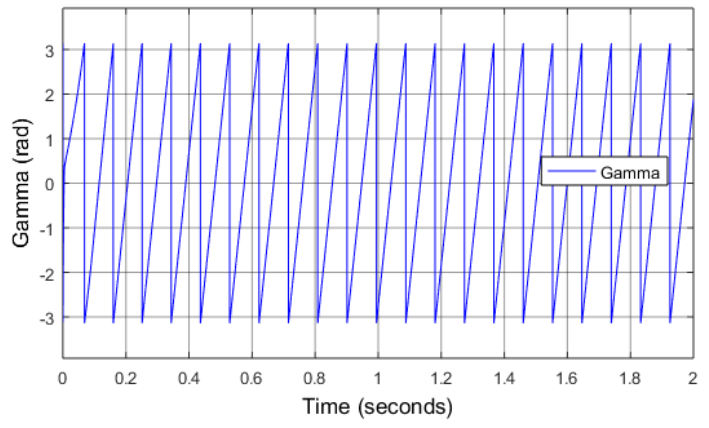

(d) Rotor flux angle

Fig. 9: The FOC using the current model for hysteresis current controller at a load of 10 (N.m). 


\section{Conclusion}

The paper proposes an improvement by applying the current model for the FOC method with the hysteresis current controller in the induction motor drive. The improving method has generated the periodic rotor flux angle signal. The rotor flux angle periodically changes according to the motor speed in the range $[-\pi \pi]$ during the operation, which maintains the stable operation of IMD against the date overflow error; thus, it is more suitable for the experimental model. The simulations have demonstrated the effectiveness of the proposed method. The improving models' control features for the rotor speed, stator current, and rotor flux responses are quick and precise in a wide speed range.

\section{References}

[1] Chan, T.F., \& Shi, K. (2011). Applied intelligent control of induction motor drives. John Wiley $\&$ Sons.

[2] Lee, K., Ahmed, S., \& Lukic, S.M. (2017). Universal restart strategy for scalar (V/f) controlled induction machines. IEEE Transactions on Industry Applications, 53(6), 5489-5495.

[3] Karthik, D., \& Chelliah, T.R. (2016). Analysis of scalar and vector control based efficiency-optimized induction motors subjected to inverter and sensor faults. IEEE International Conference on $\mathrm{Ad}$ vanced Communication Control and Computing Technologies (ICACCCT), 462-466.

[4] Pugachev, A. (2017). Efficiency increasing of induction motor scalar control systems. IEEE International Conference on Industrial Engineering, Applications and Manufacturing (ICIEAM), 1-5.

[5] Verma, P., Saxena, R., Chitra, A., \& Sultana, R. (2017). Implementing fuzzy PI scalar control of induction motor. IEEE International Conference on Power, Control, Signals and Instrumentation Engineering (ICPCSI), 1674-1678.
[6] Vladimir, P., \& Dmitry, S. (2018). To issue of designing scalar closed-loop controllers for frequency controlled induction motor drives. IEEE 17th International Ural Conference on AC Electric Drives (ACED), 1-4.

[7] Kohlrusz, G., \& Fodor, D. (2011). Comparison of scalar and vector control strategies of induction motors. Hungarian Journal of Industry and Chemistry, 39(2), 265-270.

[8] Alexandridis, A.T., Konstantopoulos, G.C., \& Zhong, Q.C. (2015). Advanced integrated modeling and analysis for adjustable speed drives of induction motors operating with minimum losses. IEEE Transactions on Energy Conversion, 30(3), 1237-1246.

[9] Ma, X., Ren, J., Zhao, L., Ge, Q., Li, Y., \& Zhao, Z. (2013). Close-loop induction motor rotor flux field-oriented control in single wave voltage feeding. IEEE International Conference on Electrical Machines and Systems (ICEMS), 2072-2076.

[10] Mon-Nzongo, D.L., Jin, T., Ekemb, G., \& Bitjoka, L. (2017). Decoupling network of field-oriented control in variable-frequency drives. IEEE Transactions on Industrial Electronics, 64(7), 5746-5750.

[11] Kumar, A., \& Ramesh, T. (2015). Direct field oriented control of induction motor drive. IEEE Second International Conference on Advances in Computing and Communication Engineering, 219-223.

[12] Li, W., Xu, Z., \& Zhang, Y. (2019). Induction motor control system based on FOC algorithm. IEEE 8th Joint International Information Technology and Artificial Intelligence Conference (ITAIC), 1544-1548.

[13] Banerjee, T., Bera, J.N., Chowdhuri, S., \& Sarkar, G. (2016). A comparative study between different modulations techniques used in field oriented control induction motor drive. 2nd IEEE International Conference on Control, Instrumentation, Energy \& Communication (CIEC), 358-362.

[14] Purnata, H., Rameli, M., \& Effendie, A.R. (2017). Speed control of three phase induction motor using method hysteresis space 
vector pulse width modulation. IEEE International Seminar on Intelligent Technology and Its Applications (ISITIA), 199-204.

[15] Harshitha, H.M., Dawnee, S., \& Kumaran, K. (2017). Comparative study of fixed hysteresis band current controller and adaptive hysteresis band current controller for performance analysis of induction motor. IEEE International Conference on Energy, Communication, Data Analytics and Soft Computing (ICECDS), 552-558.

[16] Farah, N., Talib, M.H.N., Ibrahim, Z., Isa, S.M., \& Lazi, J.M. (2017). Variable hysteresis current controller with fuzzy logic controller based induction motor drives. 7 th IEEE International Conference on System Engineering and Technology (ICSET), 122127.

[17] Haq, H., Imran, M.H., Okumus, H.I., \& Habibullah, M. (2015). Speed control of induction motor using FOC method. Int. Journal of Engineering Research and Applications, 5(3), 154-158.

[18] Tran, C.D., Brandstetter, P., Dinh, B.H., Ho, S.D., \& Nguyen, M.H.C. (2018). Current-Sensorless Method for Speed Control of Induction Motor Based on Hysteresis Pulse Width Modulation Technique. Journal of Advanced Engineering and Computation, 2(4), 271-280.

[19] Brandstetter, P. (2014). Electrical Drive III. Ostrava University.

[20] Yousef, A.Y., \& Abdelmaksoud, S.M. (2015). Review on field oriented control of induction motor. Int. J. Res. Emerg. Sci. Technol.(IJREST), 2, 5-16.

\section{About Authors}

Cuong Dinh TRAN was born in Vietnam in 1982. He received a Ph.D. degree in Electrical Engineering from VSB-Technical University of Ostrava, Czech Republic, in 2020.
Now, he is a lecturer at the Faculty of Electrical-Electronic Engineering at Ton Duc Thang University, Ho Chi Minh City, Vietnam. His research interests are the application of modern control methods and intelligent algorithms in induction motor drives.

Pavel BRANDSTETTER was born in Ostrava, Czech Republic, 1955, 1 June. He received the M.Sc. and Ph.D. degrees in Electrical Engineering from Brno University of Technology, Czech Republic, in 1979 and 1987, respectively. He is currently a full professor in Electrical Machines, Apparatus and Drives and dean of Faculty of Electrical Engineering and Computer Science at VSB-Technical University of Ostrava. Research activities include modern control methods of AC drives, for example, sensorless control of the IM and PMSM drives using different types of observers.

Bach Hoang DINH received a Ph.D. degree in Electrical Engineering from Heriot-Watt University, Edinburgh, the United Kingdom, in 2009. He received the $\mathrm{BE}$ and the $\mathrm{ME}$ degrees in Electrical Engineering from Vietnam National University - Hochiminh City in 1995 and 1998, respectively. Bach Dinh is currently the head of the Electrical Engineering Department, Faculty of Electrical-Electronic Engineering at Ton Duc Thang University. His research interests are intelligent and optimal control, computer vision, robotics, power electronics, SCADA, and industrial communication networks. He is a member of the IEEE Industrial Electronics Society.

Chau Si Thien DONG was born in Ho Chi Minh City, Vietnam. She received a Ph.D degree in Electrical Machines, Apparatus and Drives from VSB - Technical University of Ostrava in 2017. She is now the lecturer in the Faculty of Electrical and Electronics Engineering of Ton Duc Thang University. Her research interests include nonlinear control, adaptive control, robust control, neural network, and application of modern control method in the control of electrical drives. 